\title{
Evaluation of Loss Effect on Optimum Operation of Variable Speed Micro-hydropower Energy
}

\section{Conversion Systems}

\author{
Hossein Iman-Eini ${ }^{1}$, David Frey ${ }^{2}$, Seddik Bacha ${ }^{2}$, Cedric Boudinet ${ }^{2}$, and Jean-Luc Schanen ${ }^{2}$ \\ ${ }^{1}$ School of Electrical and Computer Engineering, College of Engineering, University of Tehran, Tehran, Iran \\ ${ }^{2}$ Grenoble Electrical Engineering Laboratory, Grenoble Alpes University, 38402 Grenoble, France \\ Corresponding author e-mail address: imaneini@ut.ac.ir
}

\begin{abstract}
This paper evaluates the effect of converter and generator losses on the maximum power point (MPP) of variable speed micro-hydropower energy conversion systems. As a case study, a semi-Kaplan micro-hydropower turbine with a permanent magnet (PM) generator and a back-to-back full converter is considered. Using the analytical model, different loss terms, such as converter losses, PM generator losses and mechanical losses are calculated at different shaft speeds. Then, the curves of turbine power and injected power to the grid are extracted as a function of turbine speed. It is shown that the maximum attainable power of the variable-speed hydropower system does not correspond to the MPP of hydraulic turbine. In other words, to get the maximum power from the whole hydropower system, it is necessary to consider power losses of the electric generator and power electronic interface between the turbine and the grid. These power losses can change the power-speed characteristics or MPP location of the hydropower system. According to this fact, the conventional MPP tracking (MPPT) algorithms which try to track the MPP of hydraulic turbines fail to extract the maximum power. Hence, a modified perturb and observe (P\&O) MPP tracking algorithm is proposed for the variable speed hydropower systems to increase their efficiency. The modified tracking algorithm finds the "optimum MPP" automatically and without the extra calculations. Also, the injected power to the grid is increased $3.7 \%$ when the modified algorithm is applied to the studied case study. Finally, the validity of theoretical claims is verified by experimental tests on a 5 kW hardware prototype.
\end{abstract}

Keywords- Full converter, Loss calculations, Micro-hydropower, MPPT algorithm, Permanent magnet synchronous generator, Variable speed hydropower system

\section{1- Introduction}

Hydropower is one of the earliest and most commonly used renewable sources of electricity in the human life. It represents more than $16 \%$ of the global electricity generation [1], and is the largest global renewable energy source [2]. This source of energy can be converted to electricity via the hydraulic turbine and electric generator. The size of hydraulic turbine may vary from several KW to hundreds of $\mathrm{MW}$, where the term micro-hydropower is used for the turbines with a capacity lower than $100 \mathrm{~kW}$ [3]. In micro-hydropower stations, the plant is usually installed in a run-of-river manner with a small reservoir or no reservoir and the water head is low. Such hydropower stations represent an environmentally friendly solution, since they do not interfere with the rivers flows [4].

The early hydropower stations were of fixed speed type. This kind of stations suffers from two main problems: 1-inability to produce power in the whole range of water head and 2-low efficiency in partial generation or under off-design operating condition [5]. Some references have focused on the hydraulic design and flow characteristics optimization of hydraulic machineries to increase efficiency and reduce energy loss. In [6], unsteady cavitation flows under off-design conditions and their impacts on the efficiency and the operational stability are studied. In [7], a systematic investigation into the influence of tip clearance size on energy performance and pressure fluctuation for a mixed-flow hydraulic machine is conducted. Ref. [8] evaluates the role of blade rotational angle in the energy performance and pressure fluctuation of the mixed-flow hydraulic machine through an experimental measurement and numerical simulation.

By recent advances in the power electronics, the variable speed operation can be employed for the hydropower systems similar to modern wind turbine energy conversion systems (WTECs). This technology allows 
controlling the turbine speed in a wide range of water flows and water heads. It has higher efficiency than alternative approaches and lower operating costs. Moreover, it can help to improve dynamic stability of the turbine at off-design condition [9]. The cavitation effect can be mitigated and the drive train can be simplified more. Also, by the increase of total generated power, the income of hydropower station increases [10].

The literature review shows that two approaches have been developed for variable speed hydropower and WTEC stations, which are Doubly-Fed Induction Generator (DFIG) and Full Power Converter (FPC) back-to-back connection with synchronous generator [11]. The main goal in these approaches is to adjust the turbine speed in a wide range of operating conditions to achieve the maximum efficiency. To find the optimum operating speed, there are two general approaches: indirect and direct approaches [12]. In indirect approaches, the optimum operating point is estimated according to the data of sensors and existing characteristic curves of hydraulic turbines in lookup tables. For example, reference [13] measures water head and water flow on-line to determine the appropriate turbine blade positions according to hill-diagrams of Kaplan turbine. Also, reference [14] employs a direct power control approach to directly control the injected power to the grid without the speed control loop. This method, however, needs data of water flow, shaft speed and turbine dimensions to estimate the reference power by mathematical models. In brief, necessity to some expensive sensors and inability to adapt the control system to changes of hydraulic system are main drawbacks of the indirect approach [12].

On the other side, direct methods are based on searching algorithms and are generally independent from the turbine parameters and do not need expensive sensors. These approaches have been well developed for wind energy systems and are categorized as tip speed ratio (TSR) control, optimal torque (OT) control, power signal feedback (PSF) control, perturb and observe (P\&O) control, artificial intelligent methods, and hybrid control techniques [15-20]. In all of these methods, the controller is designed to track the MPP of turbine and to get the maximum power in a wide range of operating conditions. In contrast to WTECs, a few papers have been presented in the field of variable speed hydropower systems to track the MPP of water turbine [21-23]. Reference [21] introduces an adaptive $\mathrm{P} \& \mathrm{O}$ algorithm for micro hydropower systems. It employs an adaptive coefficient $K$ which increases in the tracking phase and decreases once the MPP is reached. This idea allows reducing the mechanical shaft vibrations. The performance of adaptive P\&O algorithm has been improved in [22] by adding an active disturbance rejection control to the MPPT loop. A modified phasor extremum seeking control has also been proposed in [23] as an MPPT tool for micro hydropower plants. This method has the advantage of fast convergence to the extremum (or the peak power point) compared to previous algorithms.

All above methods try to find the MPP of hydraulic turbines in a short time and with the minimum stress on the mechanical parts to extract the maximum power. But, as it is shown in this paper, the maximum attainable power of the variable-speed hydropower system does not correspond to the MPP of hydraulic turbine. In other words, to get the maximum power from the whole hydropower system, it is necessary to consider power losses of the electric generator and power electronic interface between the turbine and the grid. In fact, these power losses can change the power-speed characteristics or MPP of the hydropower system. Hence, to discriminate the MPP of the hydraulic turbine from the MPP of the whole system, the term "optimum MPP" is used for the latter and is investigated in detail in this paper.

According to literature review, some references such as [24-27] have mentioned the shift of MPP in wind energy conversion systems. Reference [24] has considered a $20 \mathrm{KW}$ wind turbine connected to a permanent magnet synchronous generator (PMSG), where the stator terminals are connected to a diode rectifier and a 3phase voltage source inverter. This reference calculates PMSG losses with considering a constant flux density for the machine (in all operating points) and evaluates the loss effect on the optimum MPP. The loss model, however, is simple and it does not consider the converters losses and the effect of harmonic terms (caused by diode rectifier) on machine losses. Reference [25] has used a similar topology as [24] but it replaces the synchronous machine with an air-cored PMSG. It proposes an equivalent circuit for the loss calculation of air-cored PMSG. But, same as [24], the converters losses are not considered and the loading effect on the flux density is not evaluated. Reference [26] has presented a hybrid tracking algorithm to track the MPP efficiently. Using some experiments, it shows that the MPP of whole system must be tracked instead of MPP of wind turbine to achieve higher efficiency. This reference, however, does not provide any theoretical justification for its claim. The author of [27] has proposed an interesting maximum efficiency point tracking method for a variable speed small hydropower plant which employs two control loops: one as water level governor and one as an adaptive load controller to find the 
optimal operation point of the system and to maximize the system efficiency. In [27], the generated active power at the grid side is used to find the optimum operating point and to maximize the total efficiency. But, there is no analysis about the effect of different loss terms on the optimum operating point of the system.

In this paper, due to lack of knowledge about the impact of internal system losses on the MPP of a variablespeed micro hydropower system, a complete theoretical analysis is presented for the calculation of different loss terms at various speeds. As a case study, a semi-Kaplan turbine coupled to a PM synchronous generator is considered. The micro-hydropower system is connected to the grid by a back-to-back power electronic unit and the variable-speed control is applied to the turbine. Different loss terms as a function of shaft speed are calculated and demonstrated to show their impacts on the MPP of total system. It is proved that the MPP of whole system does not correspond to the MPP of the hydraulic turbine. Also, a modified MPP tracking algorithm is proposed to extract the maximum power of the whole system. The experimental results are provided to verify the validity of analytical achievements.

\section{Structure of micro-hydropower generation system}

The studied hydropower generation system in this paper has three main parts: micro-hydropower turbine, synchronous generator, and power electronic unit between the generator and the grid which are explained in the following subsections.

\subsection{Micro-Hydropower turbine}

In this paper, a propeller (or semi-kaplan) turbine with fixed blades and fixed guide vanes is considered. This kind of turbine is a reaction turbo-machine and has a similar operating principle to standard wind turbines. As it is shown in Fig.1, the turbine is a vertical axis machine which is fed by a penstock linked usually to a reservoir which is supplied by an upstream canal. This configuration is suitable for run-of-river and low head power generation stations.

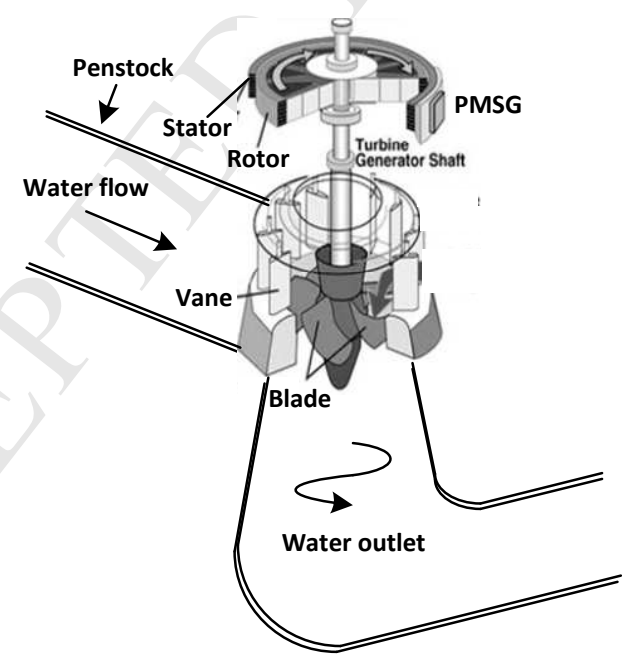

Fig.1. Schematic of semi-Kaplan turbine with fixed guide vanes and fixed blades

The turbine converts the available energy of the water to mechanical power. The available hydraulic power depends on the water flow rate (discharge) and water head which is given by [21]:

$P_{h}=\rho g H Q$

where $\rho$ is the specific density of water $\left(\mathrm{kg} / \mathrm{m}^{3}\right), \mathrm{g}$ is the acceleration due to gravity $\left(9.8 \mathrm{~m} / \mathrm{s}^{2}\right), \mathrm{H}$ is the net water head $(\mathrm{m})$ and $\mathrm{Q}$ is the water flow rate $\left(\mathrm{m}^{3} / \mathrm{s}\right)$. The extractable mechanical power $\mathrm{P}_{\mathrm{T}}$ is related to the hydraulic power by the following equation: 
$P_{T}=\eta_{h} P_{h}=\eta_{h} \rho g H Q$

being $\eta_{h}$ the hydraulic turbine efficiency. Since the turbine will be operated over a wide range of rotor speeds, an accurate model which precisely reflects the behavior of hydraulic system at different operating conditions is needed [28]. The accurate models can be obtained from the so-called efficiency hill charts. These charts are usually given by manufactures or can be obtained by experimental tests on a scaled down system. The hill charts represent constant efficiency curves as a function of flow rate $Q$ and rotational speed $\omega_{m}$ at different water heads H. For simplicity, it is possible to consider the water head fixed and to model the system in a 2D plane [21]. Then, to achieve the optimal operation, the control system should compensate the effect of water head variations in reality and looks for the MPP. This goal can be achieved by MPP tracking (MPPT) algorithms which are independent of system parameters and do not need water flow and water head sensors, such as P\&O algorithm.

In this paper, the efficiency curves for the utilized semi-Kaplan turbine are modeled based on the approach in $[21,28]$. According to [28], the efficiency curve of a fixed-head propeller (or semi-Kaplan) turbine at steady state condition can be modeled by the following formula:

$$
\begin{aligned}
& \eta_{h}(\lambda, Q)=0.5\left[\left(\frac{90}{\lambda_{i}}+Q+0.78\right) e^{\frac{-50}{\lambda_{i}}}\right](3.33 Q) \\
& \frac{1}{\lambda_{i}}=\left[\frac{1}{(\lambda+0.089)}-0.035\right], \text { and } \lambda=\frac{R A \omega_{m}}{Q}
\end{aligned}
$$

where $R$ is the radius of turbine $(m), A$ is the area swept by the rotor blades $\left(m^{2}\right)$, and $\omega_{m}$ is the shaft speed $(\mathrm{rad} / \mathrm{s})$. The validity of (3) has been verified in [28] by different experimental measurements and curve fittings. Again it is point out that (3) is valid for fixed-head propeller turbines and the effect of water head variations will be compensated by the control system.

Fig.2 demonstrates the steady-state power-speed curves according to (2) and (3) for a turbine with a fixed head of $\mathrm{H}=1 \mathrm{~m}$ and the radius of $\mathrm{R}=0.27 \mathrm{~m}$. These curves are illustrated at different water flow rates and corresponding to each curve there is a unique MPP. The existing control techniques try to track these MPPs when the water flow rate or water head changes [28].

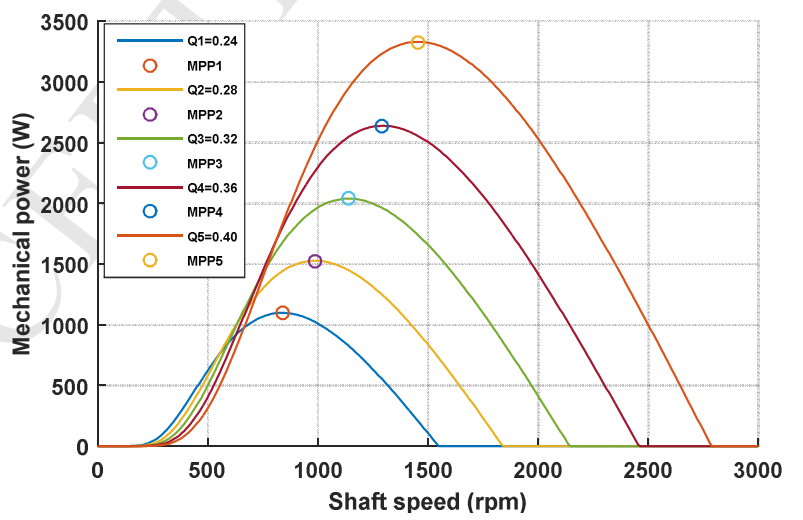

Fig.2. Semi-Kaplan turbine power-speed curves at different water flow rates and fixed head of $\mathrm{H}=1 \mathrm{~m}$

\subsection{Drive train and power electronic interface}

As it is seen in Fig.1, the turbine shaft is connected to the generator shaft with a rigid coupling. Then, with the turning of hydraulic turbine, the mechanical power is generated and the mechanical toque is transferred to the generator shaft. Hence, the turbine torque can be given by 
$T_{T}=\frac{P_{T}}{\omega_{m}}=\frac{\eta_{h} P_{h}}{\omega_{m}}$

On the other side, the synchronous generator generates the electromagnetic torque $T_{e m}$ and the motion equation can be written as [29]

$T_{T}-T_{e m}=J \frac{d \omega_{m}}{d t}+B \omega_{m}$

where $\mathrm{J}$ is the total moment inertia of the turbine-generator coupling and $\mathrm{B}$ represents the rotational viscous coefficient.

The block diagram of power electronic interface is illustrated in Fig.3. As it is seen, a back-to-back full converter is employed and the generated electric power is transferred via it. In this structure, the machine side converter is responsible for the speed control of hydraulic turbine and the grid side converter regulates the dc bus voltage and controls the injected currents to the grid.

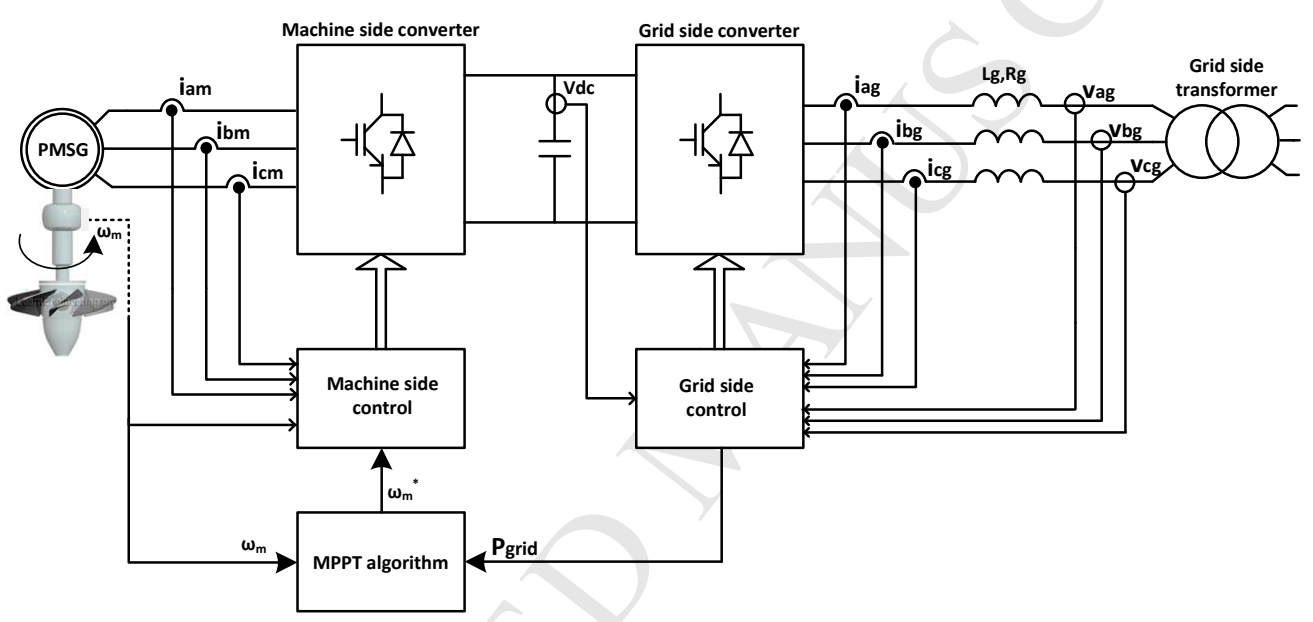

Fig.3. Block diagram of the micro hydro-power system and power electronic interface

\subsection{Control of machine side and grid side converters}

The machine side converter is controlled by the vector control theory. This theory is widely used in the control of electrical machines and three-phase power electronic systems [29]. In this analysis, the three-phase variables are converted to vectors with orthogonal $d-q$ axis terms in a synchronous rotating $d-q$ axis system and consequently reduce the system order and simplify the calculations. In the following, the vector control of PMSM is obtained by fixing the rotor magnet axis $\left(\lambda_{m}\right)$ to the direct axis (d-axis) of stator winding. In other words, the rotor flux is assumed to be concentrated along the stator $d$-axis while there is zero flux along the $q$-axis. Moreover, the rotor reference frame is considered for modeling which means that the equivalent $d$ - and $q$-axis stator windings are transformed to the reference frame that is revolving at rotor speed $\omega_{r}$. Using these assumptions, the stator $d$ - and $q$-axis voltage equations and the torque equation can be written as [29]:

$$
\begin{aligned}
& \left\{\begin{array}{l}
u_{d}=\left(R_{s} i_{d}+L_{d} \frac{d i_{d}}{d t}\right)-\omega_{r} L_{q} i_{q} \\
u_{q}=\left(R_{s} i_{q}+L_{q} \frac{d i_{q}}{d t}\right)+\omega_{r} L_{d} i_{d}+\omega_{r} \lambda_{m}
\end{array}\right. \\
& T_{e m}=\frac{3}{2} P_{n}\left(\lambda_{m} i_{q}+\left(L_{d}-L_{q}\right) i_{d} i_{q}\right)
\end{aligned}
$$


where $\left(U_{d}, U_{q}\right)$ and $\left(i_{d}, i_{q}\right)$ represent stator voltage and current variables in d-q axis system, $L_{d}$ and $L_{q}$ are called dand $q$-axis inductances, respectively. $P_{n}$ is the number of pole pairs, $T_{e m}$ is the electromagnetic torque, and $\omega_{r}$ is the electrical rotor speed and is equal to $P_{n} \omega_{m}$. In this paper, $i_{d}=0$ control is employed to achieve a linear relation between the electromagnetic torque and the $q$-axis current. The reference of $q$-axis current $i_{q}{ }^{*}$ will be defined by the speed regulator, where the speed reference is determined by the upstream MPPT controller.

The function of grid side controller is to control the dc bus voltage and to control the injected current to the grid. Using a 3-phase PLL, the phase of grid voltage is determined and a current with the desired power factor (in this paper, unity power factor) is injected.

\section{Calculation of different loss terms}

In this part, different loss terms, including the mechanical loss, the generator loss, converters losses and the filter loss are calculated at steady state condition. The final goal is to obtain the loss terms at different operating points of the turbine. In other words, similar to power-speed curves in Fig.2, the power loss curves will be calculated in " $\mathrm{n}$ " distinct operating points (or speeds). In this paper, the " $\mathrm{k}$ "th" operating point (or speed) is defined by:

$$
\omega_{m, k}=\omega_{m, k-1}+\Delta \omega_{m} \quad, k=1,2, \ldots, n
$$

where, $\Delta \omega_{m}$ is a fixed value, e.g., $1 \mathrm{rad} / \mathrm{s}$, and determines the amount of speed change in each step. In the provided algorithm for power loss calculations, the operating speed will be increased from zero to the maximum value and the generator phase current $\left(\left|I_{s}\right|\right.$, where $\left.\left|I_{s}\right|=\left|i_{q, k}\right|\right)$ and the grid phase current $\left(I_{g, k}\right)$ will be calculated to estimate the loss terms. Noting to (5), (7), and neglecting the friction losses, one can obtain the generator q-axis current at steady-state as:

$$
i_{q, k}=\frac{T_{e m}}{1.5 P_{n} \lambda_{m}} \cong \frac{T_{T}}{1.5 P_{n} \lambda_{m}} \cong \frac{P_{T, k}}{1.5 P_{n} \lambda_{m} \omega_{m, k}}
$$

where, $i_{q, k}$ represents the stator q-axis current at $\omega_{m, k}$ and $P_{T, k}$ is the corresponding turbine power at $\omega_{m, k}$ (9) is valid for $i_{d}=0$ control and also for the case that synchronous generators with surface mounted permanent magnets are utilized. For calculation of the grid phase current, first the injected power to the grid is determined by

$$
P_{\text {grid }, k}=P_{T, k}-P_{\text {Loss }, k}
$$

where, $\mathrm{P}_{\text {loss }, \mathrm{k}}$ represents the total system losses at $\omega_{\mathrm{m}, \mathrm{k}}$. Since the loss curve is a continues function of speed, it is possible to approximate the power loss term at $\omega_{m, k}$ with the total loss term at $\omega_{m, k-1}$ (which is known from the previous iteration of the proposed loss calculation algorithm in Fig.4) if the step size $\Delta \omega_{m}$ is small enough. So, (10) can be rewritten as

$$
P_{\text {grid }, k} \approx P_{T, k}-P_{\text {Loss }, k-1}
$$

In the following parts, the procedure of power loss calculation is explained in detail. Assuming that the grid side voltage is balanced and the injected current to the grid is sinusoidal with unity power factor, the rms of injected current to the grid is obtained as

$$
I_{g, k}=\frac{P_{g r i d, k}}{3 V_{g}}=\frac{P_{T, k}-P_{L o s s, k-1}}{3 V_{g}}
$$

where $I_{g, k}$ is the rms value of phase current at $\omega_{m, k}$ and $V_{g}$ represents the rms value of grid voltage. In the following subsections, different loss terms are calculated based on the estimated current variables in (9) and (12).

\subsection{PM generator losses}

The losses in a PMSG include winding loss, core loss and permanent magnet loss, where the permanent magnet loss is neglected because the air gap field usually rotates in synchronous with the rotor, and the magnets do not 
experience a time varying field [30]. Winding loss is related to internal resistances of stator windings and can be determined by

$$
P_{W, k}=\frac{3}{2} R_{s}\left|I_{s}\right|^{2}=\frac{3}{2} R_{s}\left(i_{d, k}^{2}+i_{q, k}^{2}\right)=\frac{3}{2} R_{s}\left|i_{q, k}\right|^{2}
$$

where, $\left|I_{s}\right|$ is the amplitude of stator phase current and $R_{s}$ is the equivalent resistance of one phase and depends on winding temperature. Moreover, due to skin effect, the ac current which passes through the winding will see a lower conductor area and a greater resistance. Considering both temperature and skin effect, $\mathrm{R}_{\mathrm{s}}$ can be estimated by

$$
R_{s}=R_{d c}(1+\alpha(T-20)) \cdot\left(1+y_{s}\right)
$$

where, $R_{d c}$ is the winding dc resistance at $20^{\circ} \mathrm{c}, \alpha$ is the temperature coefficient of resistance for copper $(\alpha=0.004041), T$ is the temperature of winding at operating condition, and $y_{s}$ is the skin effect factor and can be determined according to the procedure explained in IEC 60287-1-1 standard [31].

Core loss estimation can be performed by empirical models such as Steinmetz-Model or more physical based models such as the Berotti-Model which shows the total core losses as a combination of hysteresis, eddy current, and excess losses, i.e.,

$$
P_{\text {core }}=\left(k_{h} f B^{h}+k_{e d} f^{2} B^{2}+k_{e x} f^{1.5} B^{1.5}\right) \cdot W_{\text {core }}
$$

where $f$ is the magnetization frequency, $\mathrm{B}$ is the peak value of the magnetic flux density, $\mathrm{W}_{\text {core }}$ represents the core weight, and the rest parameters are material specific parameters which can be identified either by referring to lamination material datasheet or doing some measurements and using polynomial curve fitting [32]. It is worth mentioning that the average flux density is not equal in different parts of the stator. So one may use the finite element model (FEM) tool to obtain the average flux density at different parts of the stator and to apply (15) for power loss calculation at each part [33]. Some other references have proposed a method for estimation of average flux density at the stator tooth and yoke, i.e., $B_{t}$ and $B_{j}$, according to the dimensional and design parameters of the machine and eliminated the necessity for FEM tool [34]. The average flux density in the tooth and yoke can be derived from $d$ - and q-axis flux linkages as [34]

$$
\begin{aligned}
& B_{t d, q}=\frac{\lambda_{d, q}}{S_{t c}} \rightarrow B_{t}=\sqrt{B_{t d}{ }^{2}+B_{t q}{ }^{2}} \\
& B_{j d, q}=\frac{\lambda_{d, q}}{S_{j c}} \rightarrow B_{j}=\sqrt{{B_{j d}{ }^{2}+B_{j q}{ }^{2}}^{2}}
\end{aligned}
$$

Where, $\mathrm{S}_{\mathrm{tc}}$ and $\mathrm{S}_{\mathrm{jc}}$ represent the equivalent areas of stator tooth and stator yoke, respectively. The procedure of finding the equivalent $S_{t c}$ and $S_{j c}$ have been explained in [34]. In addition, flux linkages can be calculated as

$$
\left\{\begin{array}{l}
\lambda_{d}=L_{d} i_{d, k}+\lambda_{m} \\
\lambda_{q}=L_{q} i_{q, k}
\end{array}\right.
$$

Then, the total machine losses at the shaft speed $\omega_{m, k}$ can be written as

$$
P_{\text {mach }, k}=P_{W, k}+P_{\text {core }, k}
$$

\subsection{Mechanical loss}

Mechanical loss has different terms, including coupling, bearing and windage loss. Coupling loss is related to the loss of mechanical coupling between the turbine and generator shaft. Bearing loss is a mechanical friction between the rotor and the bearing and the windage loss is related to the friction between the rotor and the air. The expression of total mechanical loss at the operating speed $\omega_{m, k}$ can be given by [35]:

$$
P_{m e c h, k}=k_{b} \omega_{m, k}+k_{w} \omega_{m, k}^{2}
$$


where, $k_{b}$ and $k_{w}$ are loss parameters which depend on the rotor weight, length, shape, and shaft diameter. To determine these two parameters, one can apply a no load test on the set of turbine and generator and then to measure the power loss as a function of speed. The obtained loss-speed curve under no load condition is a sum of core loss and mechanical loss [36]. Then, the value of core loss can be calculated from (15) and subtracted from the total loss. The obtained curve can be fitted to the formula of (20), and therefore, the mechanical loss parameters, i.e., $\mathrm{k}_{\mathrm{b}}$ and $\mathrm{k}_{\mathrm{w}}$ are determined.

\subsection{Machine side converter loss}

Machine side converter is a three phase voltage source converter which is utilized for control of turbine speed. In fact, the employed controllers for the control of $i_{d}$ and iq will generate the stator $d$ - and $q$-axis voltages. Then, the PWM modulator will synthesize the abc voltages from dq components.

The loss terms in the machine side converter include conduction and switching losses of the power switches and diodes. Reference [37] explains the mechanism of power loss calculation in a voltage source inverter and a similar method with some modifications is utilized in this paper. According to [37], the average conduction losses for a power switch $\mathrm{P}_{\text {con,s }}$ and a diode $\mathrm{P}_{\text {con,d }}$ in a period can be estimated by,

$$
\begin{aligned}
& P_{c o n, s}=\left(\frac{1}{8}+\frac{M}{3 \pi}\right) r_{c e}\left|I_{s}\right|^{2}+\left(\frac{1}{2 \pi}+\frac{M}{8} \cos \theta\right) V_{c e o}\left|I_{s}\right| \\
& P_{c o n, d}=\left(\frac{1}{8}-\frac{M}{3 \pi}\right) r_{d}\left|I_{s}\right|^{2}+\left(\frac{1}{2 \pi}-\frac{M}{8} \cos \theta\right) V_{F o}\left|I_{s}\right|
\end{aligned}
$$

In (21) and (22), the i-v characteristics of the switch and diode have been approximated by linear equations of $V_{c e}=V_{c e o}+r_{c e} I_{c}$ and $V_{d}=V_{F o}+r_{d} I_{c}$. Moreover, $\left|I_{s}\right|$ is the amplitude of stator current (or generator phase current) and is obtained from $\left|I_{s}\right|=\sqrt{{i_{d, k}}^{2}+i_{q, k}^{2}} \cdot \theta$ is the phase difference between stator current and voltage, i.e., $\theta=\angle\left(u_{d}+j u_{q}\right)-\angle\left(i_{d}+j i_{q}\right)$ and $\mathrm{M}$ represents the modulation index of the converter, which is approximated by

$$
M_{1}=\left(2 \sqrt{u_{d}^{2}+u_{q}^{2}}\right) / V_{d c}
$$

where subscript 1 is used for the machine side converter and the variables $u_{d}$ and $u_{q}$ are determined from (6). In all above equations, the calculations are done at steady-state condition and the derivative terms are set to zero.

Switching energy losses of power switches (IGBTs in this paper) contain turn-on and turn-off losses, i.e., $E_{s w}=E_{o n}+E_{o f f}$, and for the diodes is equal to reverse recovery losses, i.e., $E_{s w}=E_{r r}$. The semiconductor manufacturers usually give the curves of turn-on, turn-off and reverse recovery losses as a function of current at a specific operating voltage and junction temperature. For each of these terms, the corresponding curve can be approximated by a second order polynomial. For example, $E_{\text {on }}$ curve can be approximated by

$$
E_{\text {on }}=a_{1} I_{c}^{2}+a_{2} I_{c}+a_{3}
$$

where, $I_{c}$ is the device current at the switching instant, and $a_{1}, a_{2}$, and $a_{3}$ are coefficients of second order polynomial and are obtained from curve fitting procedure. The dependency of switching energy on the supply voltage $V_{c c}$ and chip temperature can also be considered by

$$
E_{s w}=E_{s w r e f} \cdot\left(\frac{V_{c c}}{V_{c c r e f}}\right)^{K_{v}} \cdot\left(1+T C_{s w}\left(T_{j}-T_{j r e f}\right)\right)
$$

Where $\mathrm{K}_{\mathrm{v}}$ is the exponent of voltage dependency (IGBT 1.2...1.4; Diode $\sim 0.6$ ) and $\mathrm{TC}_{\mathrm{sw}}$ is temperature coefficient of switching losses (IGBT $~ 0.003$; Diode 0.005 ...0.006) [38]. In (25), the subscript ref is related to nominal test conditions which are known in the device datasheet. Noting to (24), (25) and assuming that the machine current is sinusoidal, i.e., $I_{s}=\left|I_{s}\right| \sin \alpha$, the corresponding average turn-on loss term in a fundamental cycle can be obtained as 


$$
E_{\text {on }(a v)}=\frac{1}{2 \pi} \int_{0}^{\pi} E_{\text {on }} d \alpha=\left(\frac{a_{1}\left|I_{s}\right|^{2}}{4}+\frac{a_{2}\left|I_{s}\right|}{\pi}+\frac{a_{3}}{2}\right) \cdot\left(\frac{V_{c c}}{V_{c c r e f}}\right)^{K_{v}} \times\left(1+T C_{s w}\left(T_{j}-T_{j r e f}\right)\right)
$$

Also, for calculation of turn-off and reverser recovery losses, a similar method can be employed. Considering all loss terms, the total machine side converter loss $\mathrm{P}_{\mathrm{c} 1, \mathrm{k}}$ at $\omega_{\mathrm{m}, \mathrm{k}}$ can be given by

$$
P_{c 1, k}=6 \cdot\left(P_{c o n, s}+P_{c o n, d}+f_{1} \cdot\left(E_{o n}+E_{o f f}+E_{r r}\right)\right)
$$

where, $\mathrm{f}_{1}$ represents the switching frequency of the machine side converter.

\subsection{Grid side converter loss}

Calculation of power loss in the grid side inverter is similar to the machine side converter and the same formulas are applied. In this case, the phase current is estimated by (12) and the modulation index for the grid side converter is determined by

$$
M_{2}=\left(2 \sqrt{2} \sqrt{\left(V_{g}+R_{f} I_{g, k}\right)^{2}+\left(L_{f} \omega I_{g, k}\right)^{2}}\right) / V_{d c}
$$

where, $R_{f}$ and $L_{f}$ represent the resistance and inductance value of grid side filter. The rest procedure for loss calculation is same as subsection 3.3 . So the total grid side converter loss $P_{c 2, k}$ at operating speed $\omega_{m, k}$ is expressed by

$$
P_{c 2, k}=6 \cdot\left(P_{c o n, s}+P_{c o n, d}+f_{2} \cdot\left(E_{o n}+E_{o f f}+E_{r r}\right)\right)
$$

where, $\mathrm{f}_{2}$ represents the switching frequency of the grid side converter.

\subsection{Grid side filter loss}

At the grid side, an inductive filter is utilized to filter the ac current and to keep the harmonic current lower than standard limits. This filter will lead to some copper and core losses which should be accounted in the total loss calculation. The copper loss can be obtained from (13) by knowing the filter resistance and the correction of resistance value from (14). Moreover, the core loss can be estimated by (15) with knowing the core material and thickness of utilized laminations in the inductors. So, the total loss of the filter $P_{\text {filter, }}$ at operating speed $\omega_{m, k} c a n$ be given by

$$
P_{\text {filter }, k}=3 R_{f} I_{g, k}{ }^{2}+P_{\text {core_filt }, k}
$$

\section{Evaluation of loss effect on the MPP of hydropower system}

The given flowchart in Fig.4 shows the procedure for calculation of different loss terms in a variable-speed hydropower system. Here, it is assumed that the water flow rate and water head are constant and the turbine torque is calculated form (4). In the proposed flowchart, the shaft speed is increased from zero to the maximum value (according to (8)) and the corresponding generator phase current and the grid phase current are estimated from (9) and (12). Then, based on equations (13) to (30), different loss terms are calculated at the operating speed $\omega_{m, k}$. The total loss of the hydropower system is then determined by

$$
P_{\text {loss }, k}=P_{\text {mach }, k}+P_{\text {mech }, k}+P_{c 1, k}+P_{c 2, k}+P_{\text {filter }, k}
$$

After calculation of different loss terms at $\omega_{m, k}$ and verifying that the maximum speed has not reached, the temperature variables are estimated and the temperature dependent parameters are updated. Then, the above procedure is repeated for the next operating point (or shaft speed).

Using the proposed flowchart in Fig.4, one can obtain the curves of turbine power and injected power to the grid (as a function of shaft speed) and then evaluate the impact of different loss terms on the MPP of hydropower system. For example, for a 5-kW micro-hydropower system with the parameters given in Table I, the above procedure is performed and the corresponding curves, including the turbine power, total system loss, and the injected power to the grid are derived and shown in Fig.5. It is worth mentioning that the variation of temperature variables in Fig. 5 has been ignored. 


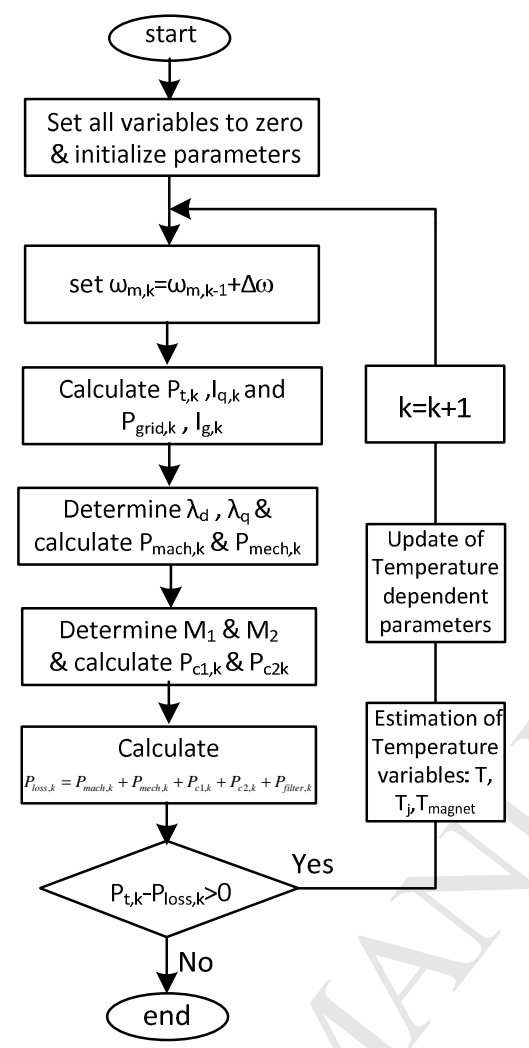

Fig.4. Flowchart of power loss estimation in the micro hydro-power system

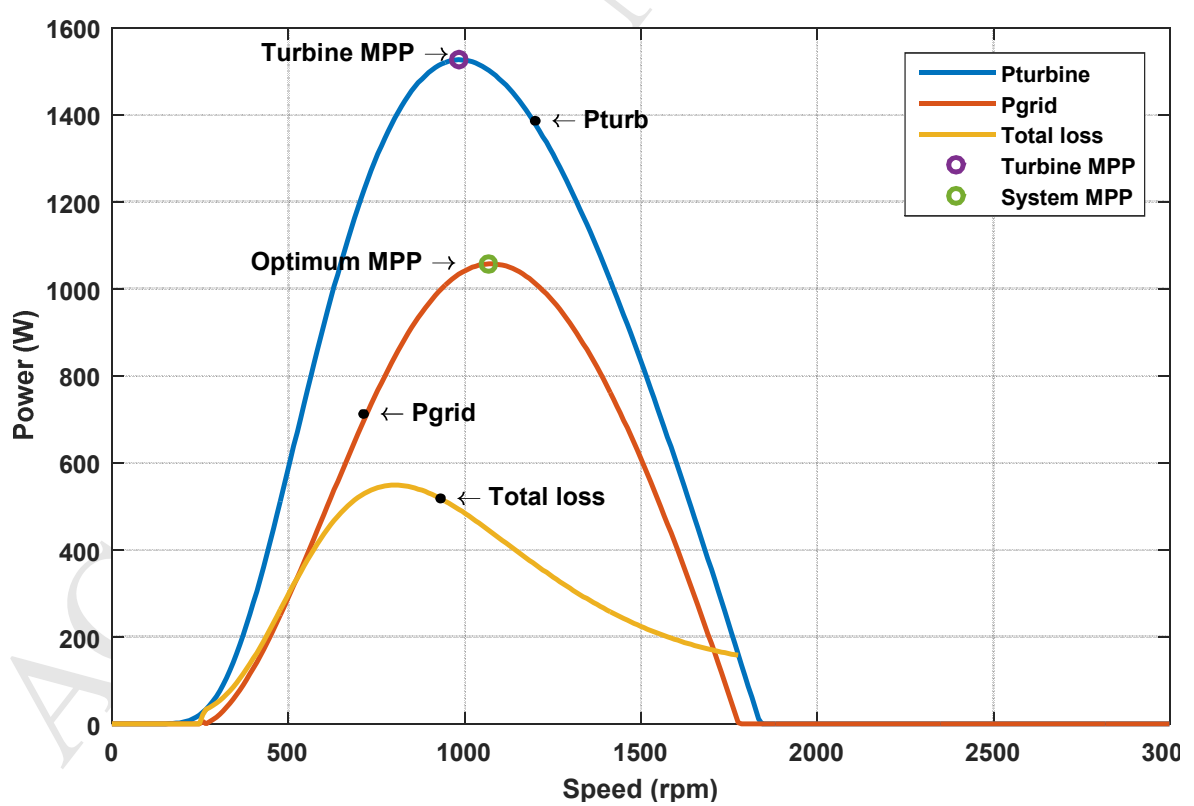

Fig.5. Calculated turbine power, injected power to the grid, and total system loss at $Q=0.28 \mathrm{~m}^{3} / \mathrm{s}$ and $\mathrm{H}=1 \mathrm{~m}$

From Fig.5, one can see that the MPP of whole hydropower system is shifted to the right when it is compared to the MPP of the hydraulic turbine. For instance, at $Q=0.28 \mathrm{~m}^{3} / \mathrm{s}$, the MPP location is shifted from 983 to 1069 rpm. In addition, the injected power to the grid increases from 1033 to $1057 \mathrm{~W}$, when the new MPP is considered. Other important variables at the MPPs of Fig. 5 are given in Table I. 
Table I. Values of important variables at the "Turbine MPP" and the "optimum MPP" ( $H=1 \mathrm{~m}$ and $\left.\mathrm{Q}=0.28 \mathrm{~m}^{3} / \mathrm{s}\right)$

\begin{tabular}{|l|c|c|}
\cline { 2 - 3 } \multicolumn{1}{c|}{} & Turbine MPP & Optimum MPP \\
\hline Turbine power (W) & 1526 & 1500 \\
\hline Injected power to grid (W) & 1033 & 1057 \\
\hline Mechanical speed (rpm) & 983 & 1069 \\
\hline Turbine torque (N.m) & 14.8 & 13.4 \\
\hline
\end{tabular}

Fig.6 shows the loss distribution among different components of the hydropower system at $Q=0.28 \mathrm{~m}^{3} / \mathrm{s}$ and $\mathrm{H}=1 \mathrm{~m}$. According to Fig.6, the PMSG and the machine side converter have the highest impact on the total loss. In addition, the maximum loss in the PMSG and the machine side converter correspond to the point of maximum torque, where the stator current has the greatest value. On the other side, the maximum loss in the grid side converter corresponds to the point of optimum MPP, where the injected current to the grid has the maximum value. It is worth noting that the grid side filter has negligible losses and is not demonstrated in Fig.6.

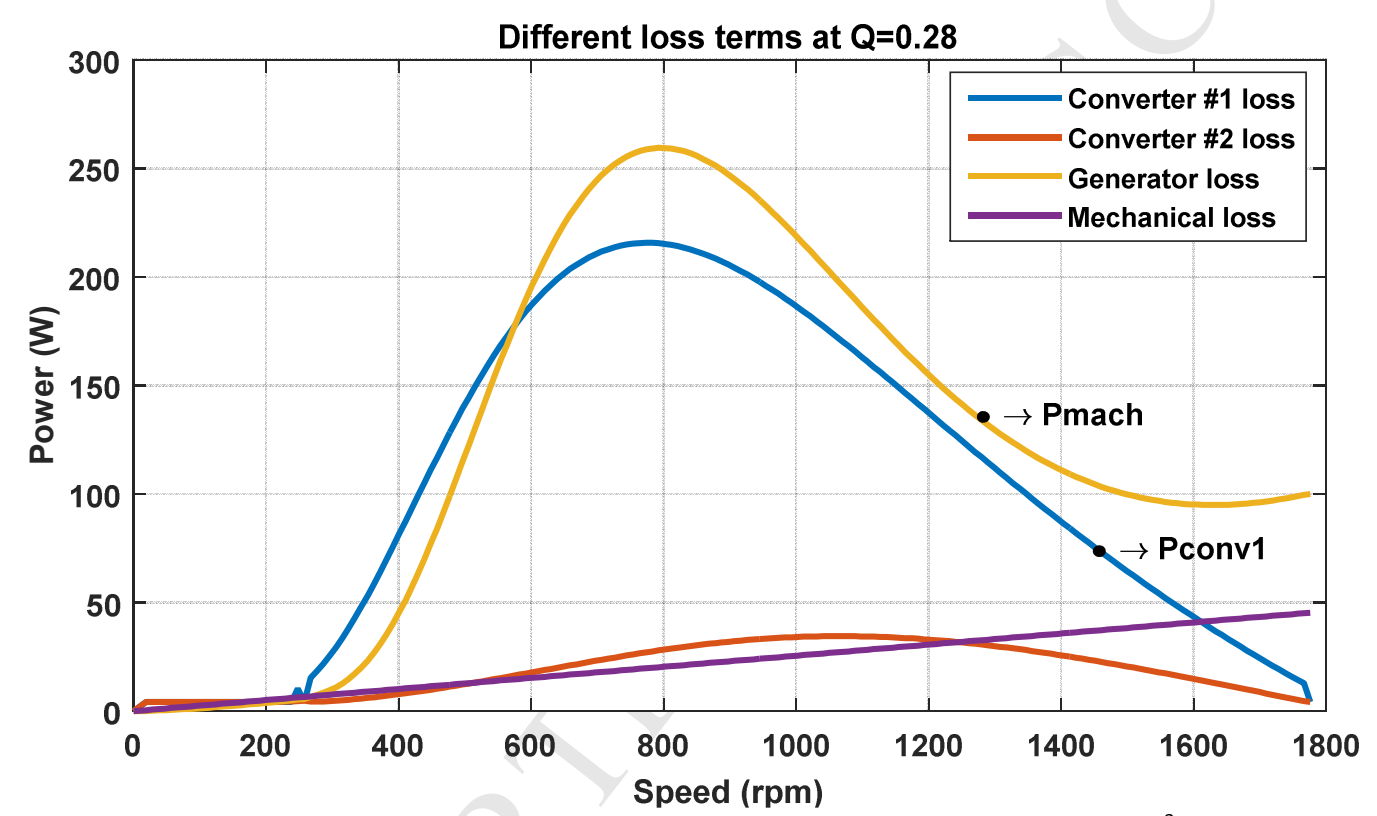

Fig.6. Different loss terms of the micro hydro-power system at $Q=0.28 \mathrm{~m}^{3} / \mathrm{s}$ and $\mathrm{H}=1 \mathrm{~m}$

\section{Experimental Verification}

To verify the validity and accuracy of obtained results in Section 3 and 4, some real-time simulations are carried out on a 5-kW hardware prototype with the parameters given in Table II. In the experimental investigations, a dc machine is utilized to emulate the behavior of micro hydro turbine (Fig.7.a) by a closed loop control on the armature current.

For the control and emulation of hydropower system, the D-SPACE system is employed which allows the realtime simulation and rapid prototyping [39]. Using this facility, all the control system can be designed in Matlab/Simulink environment and the variables can be watched and adjusted during real-time simulations. For measuring the shaft speed and electrical angle, an incremental encoder has been employed on the machine shaft. In addition, the power electronic interface is selected same as the one in Fig. 3 and vector control is employed for the control of machine side and grid side converters. 
Table II. Parameters of the micro-hydropower system utilized in analytical and experimental verifications

\begin{tabular}{|c|c|c|c|c|}
\hline \multirow{4}{*}{ Turbine } & \multicolumn{2}{|l|}{ Type } & \multicolumn{2}{|c|}{ Semi-Kaplan } \\
\hline & \multicolumn{2}{|l|}{ Radius of turbine } & $\mathrm{R}$ & $0.271 \mathrm{~m}$ \\
\hline & \multicolumn{2}{|c|}{ Area swept by turbine blades } & A & $0.23 \mathrm{~m}^{2}$ \\
\hline & \multicolumn{2}{|l|}{ Water head } & $\mathrm{H}$ & $1 \mathrm{~m}$ \\
\hline \multirow{9}{*}{ PMSG } & \multicolumn{2}{|c|}{ Number of pole pairs } & $P_{n}$ & 4 \\
\hline & \multicolumn{2}{|c|}{ Stator phase resistance } & $\mathrm{R}_{\mathrm{s}, \mathrm{dc}}$ & $0.1 \Omega$ \\
\hline & \multicolumn{2}{|l|}{ d-axis inductance } & $L_{d}$ & $0.85 \mathrm{mH}$ \\
\hline & \multicolumn{2}{|l|}{ q-axis inductance } & $\mathrm{L}_{q}$ & $0.95 \mathrm{mH}$ \\
\hline & \multicolumn{2}{|l|}{ Magnet flux } & $\lambda_{m}$ & $0.1 \mathrm{~Wb}$ \\
\hline & \multirow{4}{*}{$\begin{array}{l}\text { Core loss } \\
\text { parameters }\end{array}$} & Hysteresis & $\mathrm{K}_{\mathrm{h}}$ & $1.526 \mathrm{e}^{-5}$ \\
\hline & & Eddy current & $\mathrm{K}_{\mathrm{ed}}$ & $8.5067 e^{-7}$ \\
\hline & & Excess & $k_{\mathrm{ex}}$ & 0.003 \\
\hline & & Weight & $\mathrm{W}_{\text {core }}$ & $15 \mathrm{Kg}$ \\
\hline \multirow{3}{*}{ Turbine+PMSG } & \multirow{2}{*}{$\begin{array}{l}\text { Mechanical loss } \\
\text { parameters }\end{array}$} & Bearing & $k_{b}$ & 0.2437 \\
\hline & & Windage & $\mathrm{K}_{\mathrm{w}}$ & $1.22 \mathrm{e}^{-6}$ \\
\hline & \multicolumn{2}{|c|}{ Moment of inertia } & $\mathrm{J}$ & $0.0048 \mathrm{Kg} \cdot \mathrm{m}^{2}$ \\
\hline \multirow{20}{*}{$\begin{array}{l}\text { Power } \\
\text { electronic } \\
\text { interface }\end{array}$} & \multicolumn{2}{|l|}{ Dc bus voltage } & $\mathrm{V}_{\mathrm{dc}}$ & $400 \mathrm{~V}$ \\
\hline & \multicolumn{2}{|l|}{ Dc link capacitor } & $\mathrm{C}_{\mathrm{dc}}$ & $2.2 \mathrm{mF}$ \\
\hline & \multicolumn{2}{|c|}{ Output filter inductance } & $\mathrm{L}_{f}$ & $7 \mathrm{mH}$ \\
\hline & \multicolumn{2}{|c|}{ Output filter resistance } & $\mathrm{R}_{\mathrm{f}, \mathrm{dc}}$ & $65 \mathrm{~m} \Omega$ \\
\hline & \multicolumn{2}{|c|}{ Phase rms voltage } & $V_{a}$ & $137 \mathrm{~V}$ \\
\hline & \multicolumn{2}{|c|}{ Switching frequency } & $f_{s w}$ & $10 \mathrm{kHz}$ \\
\hline & \multicolumn{2}{|c|}{ Power switch type } & \multicolumn{2}{|c|}{ SKM 50 GB 123 D } \\
\hline & \multirow{2}{*}{\multicolumn{2}{|c|}{ Switch conduction loss parameters }} & $r_{\mathrm{ce}}$ & $28 \mathrm{~m} \Omega$ \\
\hline & & & $\mathrm{V}_{\text {ceo }}$ & $1.7 \mathrm{~V}$ \\
\hline & \multirow{2}{*}{\multicolumn{2}{|c|}{ Diode conduction loss parameters }} & $r_{d}$ & $22 \mathrm{~m} \Omega$ \\
\hline & & & $V_{f_{0}}$ & $1.2 \mathrm{~V}$ \\
\hline & \multirow{3}{*}{\multicolumn{2}{|c|}{$\begin{array}{l}\text { Switch turn on loss parameters } \\
\mathrm{E}_{\mathrm{on}}\end{array}$}} & $a_{1}$ & 0.0004747 \\
\hline & & & $a_{2}$ & 0.1518 \\
\hline & & & $a_{3}$ & 0.1197 \\
\hline & \multirow{3}{*}{\multicolumn{2}{|c|}{$\begin{array}{l}\text { Switch turn off loss parameters } \\
E_{\text {off }}\end{array}$}} & $a_{1}$ & -0.0007585 \\
\hline & & & $a_{2}$ & 0.1429 \\
\hline & & & $a_{3}$ & 0.1249 \\
\hline & Diode reverse reco & & $a_{1}$ & -0.0005622 \\
\hline & $\begin{array}{l}\text { Diode reverse reco } \\
\text { parameters } E_{\text {rr }}\end{array}$ & ry loss & $a_{2}$ & 0.07038 \\
\hline & 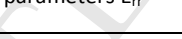 & & $a_{3}$ & -0.003097 \\
\hline
\end{tabular}

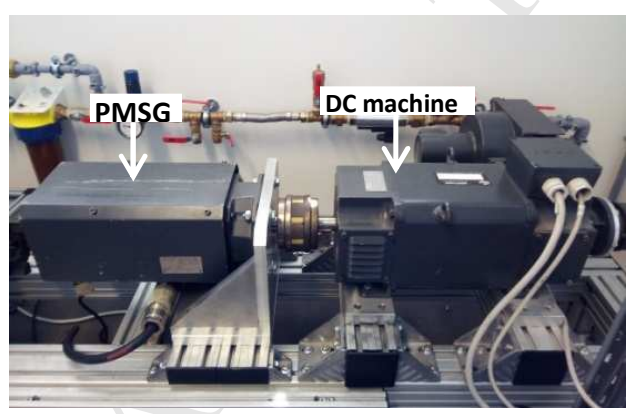

(a)

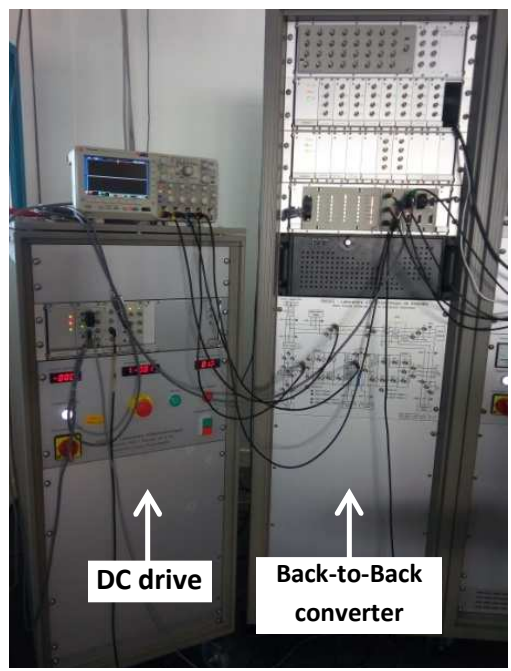

(b)

Fig.7.Utilized test-bench for emulation of hydropower system, (a) dc machine and PMSG coupling, (b) dc drive and back-to-back full converter system 


\subsection{Evaluation of loss model and the MPP location}

To compare the data of analytical model and the experimental results, the experimental data is extracted for a similar operating condition as the analytical model. To do this, the rotor speed is increased from zero to the maximum value and the corresponding turbine torque (based on already defined power-speed curves in Fig.2) is generated by the $d c$ machine and transferred to PMSG. Then, the corresponding turbine power $P_{\text {turb-exp }}$ and the injected power to the grid $\mathrm{P}_{\text {grid-exp }}$ are measured at different operating speeds.

The corresponding data from calculation model and experiments for water flows $Q=0.28$ and $Q=0.36 \mathrm{~m}^{3} / \mathrm{s}$ have been derived and demonstrated in Fig.8.a and 8.b, respectively. In these figures, the data of calculation model are shown by solid lines and the experimental data are shown by "+" symbol.

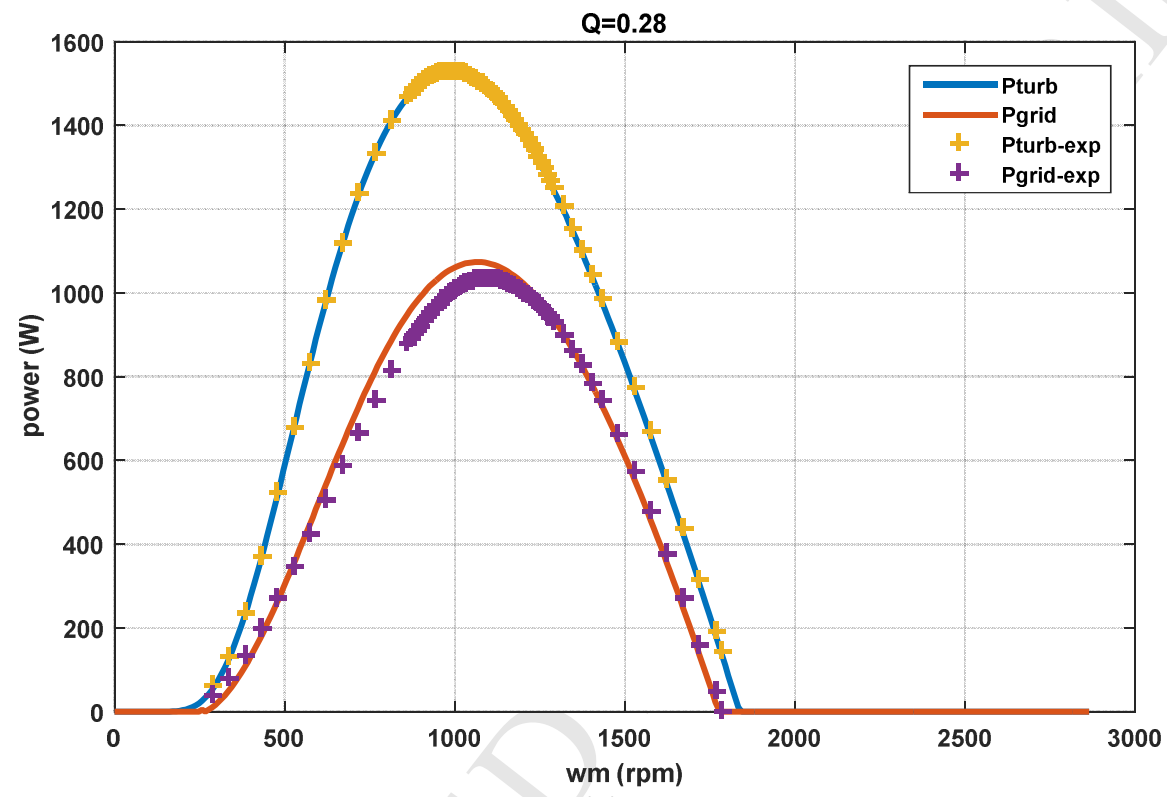

(a)

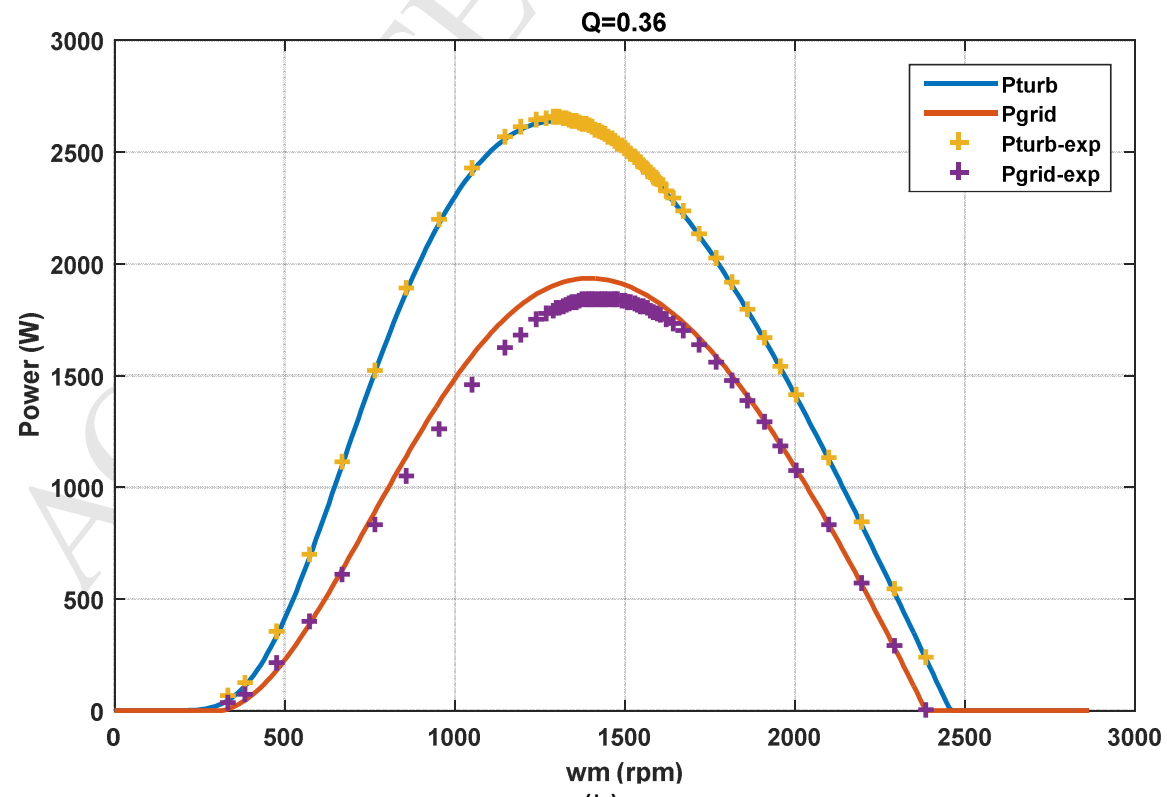

(b)

Fig.8. Turbine power and injected power to the grid based on calculation model $\left(\mathrm{P}_{\text {turb }}, \mathrm{P}_{\text {grid }}\right)$ and the experimental measurements ( $P_{\text {turb-exp }}, P_{\text {grid-exp }}$ ) at: (a) $Q=0.28 \mathrm{~m}^{3} / \mathrm{s}$, (b) $Q=0.36 \mathrm{~m}^{3} / \mathrm{s}$ 
To verify the error between the analytical model and the experimental results, the percent error formula in (32) is utilized:

$$
\% \text { Error }=\left|\frac{X_{\text {experimental }}-X_{\text {model }}}{X_{\text {model }}}\right| \times 100
$$

Using (32), one can calculate the percent error between a theoretical variable (data of model) and measured value in practice. According to (32), the percent error of turbine output power $P_{\text {turb }}$ as a function of shaft speed has been calculated and demonstrated in Fig.9.a and Fig.9.b for water flows $Q=0.28$ and $Q=0.36 \mathrm{~m}^{3} / \mathrm{s}$, respectively.

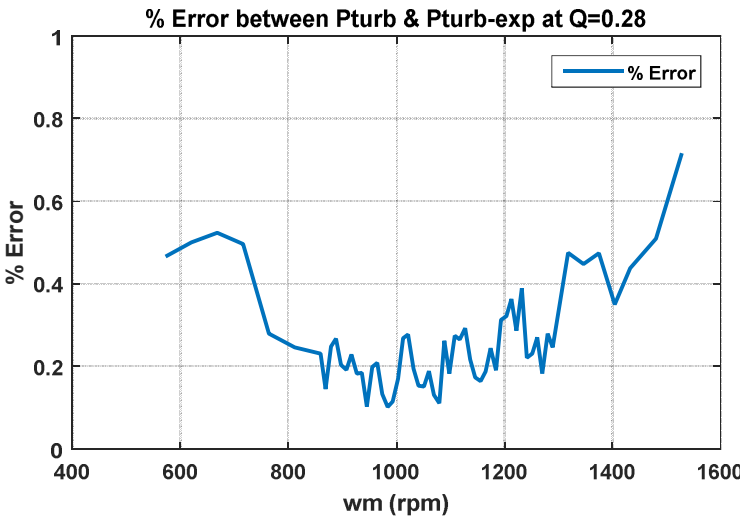

(a)

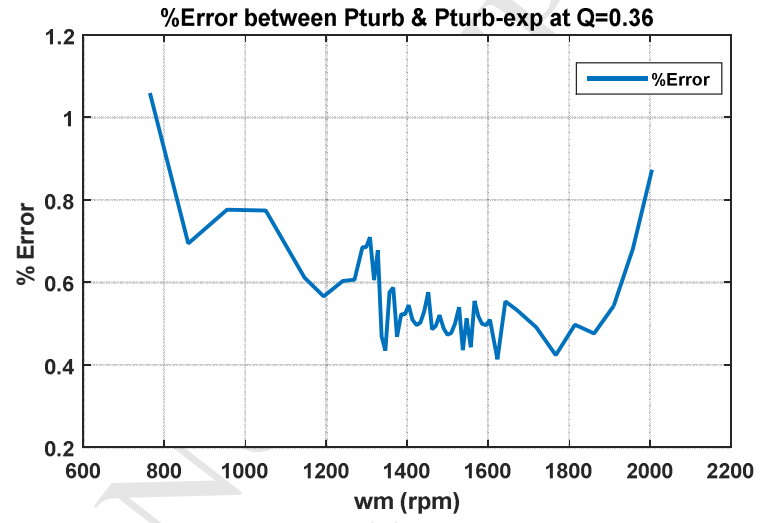

(b)

Fig.9. Percent error of the turbine output power $P_{\text {turb }}$ and $P_{\text {turb-exp }}$ as a function of shaft speed at (a) $Q=0.28$, (b) $\mathrm{Q}=0.36 \mathrm{~m}^{3} / \mathrm{s}$

As it is seen from Fig.9.a and Fig.9.b, the error is less than $1 \%$ in a wide range of operating speeds. Hence, it is concluded that there is a good agreement between the $P_{\text {turb }}$ curve and the measured one $P_{\text {turb-exp }}$ which confirms the correct modeling of the hydro turbine in practice. Hence, in continue, one can trust on the measured data for the injected power to the grid (or $\mathrm{P}_{\text {grid-exp }}$ ) and compare it with the theoretical one.

The comparison between the theoretical $P_{\text {grid }}$ curve and the measured data $P_{\text {grid-exp }}$ confirms that the presented loss modeling in sections 3 and 4 is in good agreement with the experimental results. The very small difference around the peak power point (left side of MPP) is because of neglecting the variation of temperature variables in the power loss calculations. Same as theoretical results, it is evident that the MPP of whole system does not correspond to the MPP of hydraulic turbine. This result confirms that for obtaining the maximum power of the hydropower system, one has to track the MPP of whole system instead of turbine MPP.

\subsection{Modified $P \& O$ tracking algorithm}

In practice, to find the "optimum MPP" of the hydropower system, one can employ the standard P\&O algorithm with some modifications. Fig.10.a and 10.b show the block diagram of standard P\&O algorithm and the modified algorithm in this paper, respectively. As it is seen from Fig.10.a, in the conventional P\&O, the shaft speed is perturbed and the turbine power is observed, while in the modified $P \& O$ in Fig.10.b, the shaft speed is perturbed and the injected power to the grid is observed. This technique is very simple and just needs a sensor for measuring the shaft speed. Moreover, the value of "injected power to the grid" $P_{\text {grid }}$ is estimated from the existing data for the grid side controller and no extra sensor is needed.

One should note that in Fig.10, the variable "step" is the amount of speed change in each iteration of algorithm. In this paper, the value of "step" changes as a function of $|\Delta P / \Delta \omega|$. This strategy helps reducing the mechanical perturbations, especially at steady-state. 


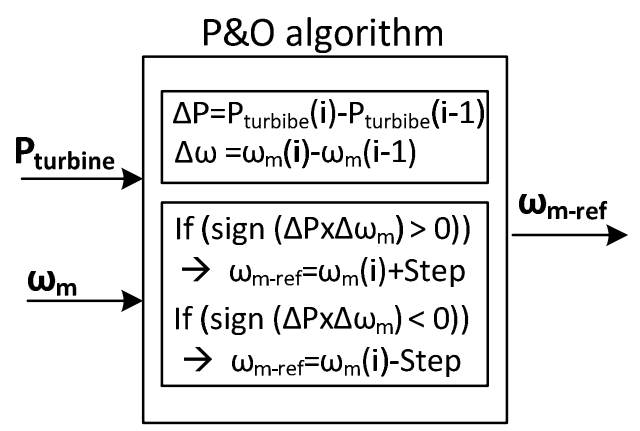

(a)

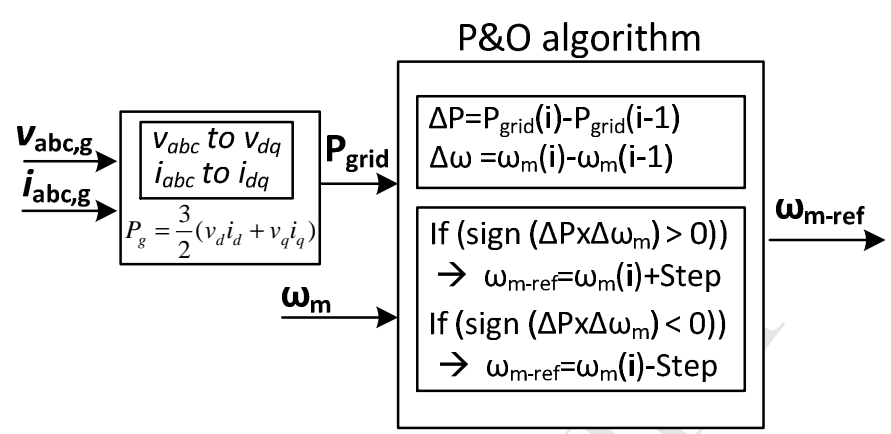

(b)

Fgi.10 Block diagram of P\&O algorithm, (a) Conventional approach, (b) Proposed approach

For finding the "optimum MPP" in Fig.10.b, there is no need to perform analytical calculations presented in sections 3 and 4 . The modified P\&O tracking algorithm can find the "optimum MPP" automatically and without the analytical calculations.

The following experiment verifies the behavior of proposed $P \& O$ algorithm. In this investigation, first the conventional P\&O algorithm (which tracks the MPP of hydraulic turbine) is applied and then the modified P\&O algorithm (which tracks the MPP of whole system) is applied. The obtained result for the condition of $Q=0.28 \mathrm{~m}^{3} / \mathrm{s}$ and $\mathrm{H}=1 \mathrm{~m}$ is shown in Fig.11.

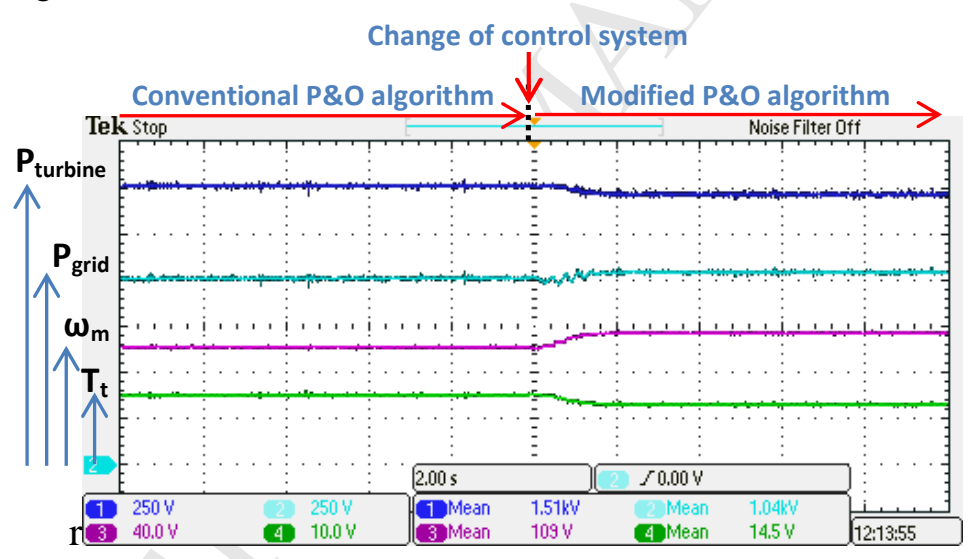

Fig.11. Waveforms of turbine power, output power, shaft speed, and turbine torque with the conventional P\&O algorithm (left half side) and with the modified P\&O algorithm (right half side)

Fig.11 shows the turbine power, injected power to the grid, mechanical speed ( $\mathrm{rad} / \mathrm{s}$ ), and turbine torque from top to bottom, respectively. The obtained steady-state data around the MPP for the conventional P\&O and the modified P\&O algorithm are given in Table III.

Table III. Comparison of the conventional P\&O and the modified P\&O around the MPP based on experiments (at $\mathrm{Q}=0.28 \mathrm{~m}^{3} / \mathrm{s}$ and $\mathrm{H}=1 \mathrm{~m}$ )

\begin{tabular}{|l|c|c|}
\cline { 2 - 3 } \multicolumn{1}{c|}{} & Conventional P\&O & Modified P\&O \\
\hline Turbine power (W) & 1530 & 1480 \\
\hline Injected power to grid (W) & 993 & 1030 \\
\hline Mechanical speed (rpm) & 978 & 1086 \\
\hline Turbine torque (N.m) & 14.9 & 13.2 \\
\hline
\end{tabular}


From Fig.11 and the given results in Table III, it is seen that after applying the modified P\&O algorithm, the turbine output power reduces $2.6 \%$ while the injected power to the grid increases $3.7 \%$. Moreover, the mechanical speed changes from 978 to $1086 \mathrm{rpm}$ and the turbine torque reduces from 14.9 to $13.2 \mathrm{~N} \cdot \mathrm{m}$ at $\mathrm{Q}=0.28 \mathrm{~m}^{3} / \mathrm{s}$. It is evident that the proposed P\&O algorithm moves the operating point from the "turbine MPP" to the "optimum MPP" and consequently more electric power is injected to the grid. This result confirms the validity of proposed P\&O algorithm and also the change of optimum operating point due to the system losses. Moreover, with the change of operating point, the generator loss and the converter loss reduces and the cooling condition becomes easier. Hence, the life time of system will improve due to lower losses and temperature stress on the system components.

\section{Conclusions}

In this paper, a propeller (or semi-Kaplan) turbine with fixed blades and fixed guide vanes was considered for the study. Then, it was shown that the maximum power point (MPP) of the variable-speed micro hydropower system does not correspond to the MPP of the hydraulic turbine. In fact, the mechanical and electrical losses of the drive train, PMSG and power electronic unit between the turbine and the grid, can change the location of "optimum MPP" in the hydropower system. In the studied example in this paper, the corresponding speed at the turbine MPP was $978 \mathrm{rpm}$ while it changed to $1086 \mathrm{rpm}$ at the "optimum MPP". Moreover, it was shown that the conventional MPP tracking approaches which track the MPP of hydropower turbine cannot find the "optimum MPP" and extract the maximum power. To solve this problem, a modified P\&O tracking algorithm was proposed in which the shaft speed was perturbed and the injected power to the grid was observed. This technique is very simple and just needs a sensor for measuring the shaft speed. Finally, the theoretical results were verified by experiments on a $5 \mathrm{~kW}$ hardware prototype and according to obtained results, the injected power to the grid can increase several percent when the modified $P \& O$ algorithm is employed. For example, in the studied example, the injected power to the grid increases 3.7\% when the modified algorithm is applied. The proposed algorithm does not depend on system parameters and can find the "optimum MPP" in a simple way.

\section{Prospective study}

The prospective study will focus on following two objectives:

- $\quad$ Investigate the modelling approach for micro hydraulic turbines to reflect precisely the turbines physical characteristics

- Investigate the variations of temperature variables in the flowchart of power loss model

\section{Acknowledgment}

This work has been funded by PSPC Innov'hydro project, which specifically brings together GE Renewable, EDF (Electricity of France), Grenoble INP and other key players in the hydroelectric sector, in France.

\section{References}

[1] Balkhair KS, Rahman KU. Sustainable and economical small-scale and low-head hydropower generation: a promising alternative potential solution for energy generation at local and regional sale. Appl Energy 2017; 188: 378-91.

[2] Yang W, Norrlund P, Bladh J, Yang J, Lundin U. Hydraulic damping mechanism of low frequency oscillation in power systems: quantitative analysis using a nonlinear model of hydropower plants. Appl Energy 2018; 212: 1138-52.

[3] Nababan S, Muljadi E, Blaabjerg F. An overview of power topologies for micro-hydro turbines. In international symposium on power electronics for distributed generation systems, 2012 PEDG. IEEE; 2012. p. 737-44.

[4] Gaudard L, Avanzi F, Michele CD. Seasonal aspects of the energy-water nexus: the case of a run-of-the-river hydropower plant. Appl Energy 2018; 210: 604-12. 
[5] Joseph A, Chelliah TR. A review of power electronic converters for variable speed pumped storage plants: configurations, operational challenges, and future scopes. IEEE J Emerg Sel Top Power Electron 2018; 6: 10319.

[6] Tan L, Zhu B, Cao S, Wang Y, Wang B. Numerical simulation of unsteady cavitation flow in a centrifugal pump at off-design conditions. Proc. Inst. Mech. Eng. Part C J. Mech. Eng. Sci. 2014, 228: 1994- 2006.

[7] Liu Y, Tan L, Hao Y, Xu Y. Energy Performance and Flow Patterns of a Mixed- Flow Pump with Different Tip Clearance Sizes. Energies 2017, 10: 1-15.

[8] Tan L, Yu Z, Xu Y, Liu Y, Cao S. Role of blade rotational angle on energy performance and pressure fluctuation of a mixed-flow pump. Proc. Inst. Mech. Eng. Part A J. Power and Energy. 2017, 231: 227-238.

[9] Trivedi C, Agnalt E, Dahlhaug O. Experimental study of a Francis turbine under variable-speed and discharge conditions, Renew Energy 2018; 119: 447-58.

[10] Chazarra M, Perez-Diaz JI, Garcia-Gonzalez J. Optimal joint energy and secondary regulation reserve hourly scheduling of variable speed pumped storage hydropower plants. IEEE Trans Power Syst 2018, 33: 103-15.

[11] Valavi M, Devillers E, Besnerais JL, Nysveen A, Nilsen R. Influence of converter topology and carrier frequency on airgap field harmonics, magnetic forces, and vibrations in converter-fed hydropower generator. To be appear in IEEE Trans Ind Appl 2018.

[12] Borkowski D. Maximum Efficiency point tracking (MEPT) for variable speed small hydropower plant with neural network based estimation of turbine discharge. IEEE Trans Energy Convers 2017; 32: 1090-98.

[13] Tessarolo A, Luise F, Raffin P, Degano M. Traditional hydropower plant revamping base on a variable-speed surface permanent-magnet high-torque-density generator. In: International conference on clean electrical power, 2011 ICCEP. IEEE; 2011. p. 350-56.

[14] Belhadji L, Bacha S, Roye D. Direct power control of variable-speed micro-hydropower plant based on propeller turbine. In: International conference on electrical machines, 2012 ICEM. IEEE; 2012. p. 2079-84.

[15] Abdullah MA, Yatim AH, Tan CW, Saidur R. A review of maximum power point tracking algorithms for wind energy systems. J Renew Sustainable Energy Rev 2012; 16: 3220-27.

[16] Mishra S, Shukla S. Comprehensive review on maximum power point tracking techniques: wind energy. In: Communication, control and intelligent systems, 2015 CCIS. IEEE; 2015. p. 464-69.

[17] Lee J, Kim Y. Sensorless fuzzy-logic-based maximum power point tracking control for a small-scale wind power generation systems with a switched-mode rectifier. IET Renew Power Gen 2016; 10:194-202.

[18] Rahmanian E, Akbari $\mathrm{H}$, Sheisi $\mathrm{H}$. Maximum power point tracking in grid connected wind plant by using intelligent controller and switched reluctance generator. IEEE Trans Sustain Energy 2017; 8:1313-20.

[19] Wei C, Zhang Z, Qiao W, Qu L. An adaptive network-based reinforcement learning method for MPPT control of PMSG wind energy conversion systems. IEEE Trans Power Electron 2016; 31: 7837-48.

[20] Chen J, Lin T, Wen C, Song Y. Design of a unified power controller for variable speed fixed-pitch wind energy conversion system. IEEE Trans Ind Electron 2016; 63: 4899-908.

[21] Belhadji L, Bacha S, Munteanu I, Rumeau A, Roye D. Adaptive MPPT applied to variable-speed microhydropower plant. IEEE Trans Energy Convers 2013; 28: 34-43.

[22] Guo B, Bacha S, Alamir M, Imaneini H. An anti-disturbance ADRC based MPPT for variable speed microhydropower plant. In: Industrial electronics conference, 2017 IECON. IEEE; 2017. p. 1783-89.

[23] Tourkey-Atta K, Johansson A, Cervantes MJ, Gustafsson T. Maximum power point tracking for micro hydro power plants using extremum seeking control. In: IEEE conference on control applications, 2015 CCA. IEEE; 2015. p. 1874-79.

[24] Tan K, Yao TT, Islam S. Effect of loss modeling on optimum operation of wind turbine energy conversion systems. In: International power engineering conference, 2005 IEEE, 2005. p. 1-9.

[25] Echenique Subiabre EJP, Mueller MA. Realistic loss modelling and mismatching in an air-cored permanent magnet generator for wind energy applications. In: IET Int. Conf. Power Electron. Machines and Drives, PEMD. IEEE; 2012. p. 1-6.

[26] Kazmi SMR, Goto H, Guo HJ, Ichinokura O. A novel algorithm for fast and efficient speed-sensorless maximum power point tracking in wind energy conversion systems. IEEE Trans Ind Electron 2011, 58: 29- 36.

[27] Borkowski D. Control strategy for maximizing conversion efficiency of a small hydropower plant. Technical Trans Electr Eng 2015; 8: 15-24.

[28] Marquez JL, Molina MG, Pacas JM. Dynamic modelling, simulation and control design of an advanced micro-hydro power plant for distributed generation applications. Int J Hydrogen Energy 2010; 35: 5772-77.

[29] Krishnan R. Electric Motor Drives-Modeling, Analysis, and Control. Prentice Hall, 2001. 
[30] Wang J, Atallah K, Chin R, Arshad WM, Lendenmann H. Rotor eddy-current loss in permanent-magnet brushless ac machines. IEEE Trans Magn 2010; 46: 2701-07.

[31] IEC Standard: Electric cables-Calculation of the current rating- Current rating equations and calculation of losses. IEC 60287-1-1, 2006.

[32] Eggers D, Steentjes S, Hameyer K. Advanced iron-loss estimation for nonlinear material behavior. IEEE Trans Magn 2012; 48: 3021-24.

[33] Choi JY, Ko KJ, Jang SM. Experimental works and power loss calculations of surface-mounted permanent magnet machines. J Magn 2011; 16: 64-70.

[34] Ni R, Xu D, Wang G, Ding L, Zhang G, Qu L. Maximum efficiency per ampere control of permanent-magnet synchronous machines. IEEE Trans Ind Electron 2015, 62: 2135- 43.

[35] Inaba N, Takahashi R, Tamura J, Kimura M, Komura A, Takeda K. A derivation of simulation model of offshore wind farm with losses and annual capacity factor considered. In: International conference on electrical machines and systems, 2012 ICEMS. IEEE; 2012. p. 1-6.

[36] Yan Y, Zhu J, Guo Y. A permanent magnet synchronous motor model with core loss. J. Japan Society of Applied Electromagnetics and Mechanics 2007; 15: 147-50.

[37] Casanellas F. Losses in PWM inverters using IGBTs. In: IEEE proceedings-electric power applications, 1994. p. $235-39$.

[38] Semikron. Determining switching losses of Semikron IGBT modules. AN 1403 application note, 2014.

[39] Ocnasu D, Gombert C, Bacha S, Roye D, Blache F, Mekhtoub S. Real-time hybrid facility for the study of distributed power generation systems. J. Revue des Energies Renouvelables 2008; 11: 343-50. 